\title{
Study of the Age Related Changes in the Lumbar Spine in Egyptian People Detected by Magnetic Resonance Imaging (MRI)
}

\author{
Gamal Abdel Salam¹, Ahmed M. S. Hegazy ${ }^{1,}$, Mohammed M. Mosaed², Osama F. Ahmed ${ }^{1}$, \\ Amgad N. Elsawy ${ }^{3}$
}

${ }^{1}$ Anatomy Department, Benha Faculty of Medicine, Benha University, Benha City, Egypt

${ }^{2}$ Anatomy Department, Al-azhar Faculty of Medicine, Al-azhar University, Assuit City, Egypt

${ }^{3}$ Orthopedic Consultant, Orthopedic Department, Ras El-Tin Hospital, Alexandria City, Egypt

\author{
Email address: \\ ahmed0562301954@yahoo.com (A. M. S. Hegazy)
}

\section{To cite this article:}

Gamal Abdel Salam, Ahmed M. S. Hegazy, Mohammed M. Mosaed, Osama F. Ahmed, Amgad N. Elsawy. Study of the Age Related Changes in the Lumbar Spine in Egyptian People Detected by Magnetic Resonance Imaging (MRI). International Journal of Clinical and Developmental Anatomy. Vol. 1, No. 2, 2015, pp. 42-51. doi: 10.11648/j.ijcda.20150102.14

\begin{abstract}
Lumbar region is the mobile part of the vertebral column which is a weight bearing region. Unfortunately, the available data detecting the lumbar spine degenerative changes by MRI are still limited, particularly in Egypt. The present study aimed to the examination of possible age related changes in the lumbar spine in Egyptian people detected by MRI. Mid sagittal MRI scan were obtained from eighty symptomless persons (30 females $37.5 \%$ and 50 males $62.5 \%$ of cases) between 25- 70 years of age. They were divided into two groups ; first group forty cases, $25-40$ years ( 21 males \& 19 females) and the second group forty cases , 41-70 years (29 males \& 11 females). From all samples, there were 38 normal (47.5\%) and the abnormal cases were $42(52.5 \%)$. It was found collectively that the abnormalities were more in males than females and that was supplemented by $\mathrm{x}^{2}$ - test (4.83) and $\mathrm{p}$ value (0.028). The following diseases were seen ; Subchondral sclerosis, osteophytes, disc degeneration, subchondral multiple small cysts, disc prolapse and spondolysis with variations in ages and sexes. In conclusuion it was found that, the lumbar region affected early by the age and more affected in males than in females.
\end{abstract}

Keywords: Lumbar, Vertebrae, Intervertebral Discs, Osteophytes, Subchondral Cysts

\section{Introduction}

The vertebral column of human is unique among the animal species in both function and aging patterns. The vertebral column has evolved in humans to be a weight bearing structure, and in turn the human vertebral column exhibits distinct aging patterns (1). Around the age of 25, the spinal column is completely developed, and thereafter, the spinal elements begin a progressive degeneration process that accelerates around the age of 50 . After the age of 50 , the degeneration of the spinal column accelerates with the increasing appearance of osteophytes, lipping, and macroporosity(2).

Increasing age brings about inevitable changes in the structure, shape and function of the human lumbar spine. The primary structural age change which occurs is a selective loss of the transversely oriented trabeculae within lumbar vertebrae, which causes them to become shorter, wider and more concave at their end-plate region. This in turn leads to a progressive alteration to the shape of the lumbar discs and, together with biochemical and histological change, brings about a reduction in spinal posture, flexibility and compliance and in the ability of the lumbar region to cope with sustained loading. This information is important for physiotherapists in their treatment of lumbar spinal disorders(3).

The components of the intervertebral disc;anulusfibrosus, nucleus pulposus, and vertebral endplates all act in concert to stabilize the spine and absorb and distribute load while allowing the spine to flex, extend, or rotate (Ashman1989)(4) and(Humzah and Soames 1988)(5). The intervertebral discs lie between the vertebral bodies, linking them together. They are the main joints of the spinal column and occupy one-third of its height. Their major role is mechanical, as they constantly transmit loads arising from body weight and muscle activity through the spinal column. They provide 
flexibility to this, allowing bending, flexion and torsion. They are approximately in the annulus and nucleus, can have several long, thin cytoplasmic projections, which may be more than $30 \mu \mathrm{m}$ long (6\&7).During growth and skeletal maturation the boundary between annulus and nucleus becomes less obvious, and with increasing age the nucleus generally becomes more fibrotic and less gel-like (8).

Like no other musculoskeletal tissue, the lumbar intervertebral disc undergoes very extensive destructive changes with age and degeneration (8). The term spondylosis refers to the bony overgrowths associated with aging of the spine. Spondylosis describes a non-specific degenerative process of the spine that may result in varying degrees of stenosis of the central spinal canal as well as the root canals. Factors contributing to this narrowing include degenerated disc, osteophyte, and hypertrophy of lamina, articular facets, ligamentumflavum, and posterior longitudinal ligament. Other relevant pathological processes include loss of the cervical lordosis and vertebral body subluxation. A congenitally narrow canal will precipitate the early development of symptoms (9).

Lumbar region is the mobile part of the vertebral column, and is often involved during accidents, degenerative disorders, congenital defects, and neoplastic metastases. Therefore, it may need instrumentation for its activity to be regained. Every structural deformity of the pedicle might effect in interference of the weight conduction mechanism and compression of neural structures (10).

The height of an intervertebral disc is influenced by several factors. There has been a tendency in earlier reports to classify this steady biochemical and histologic transformation of the disc as degenerative, but the accounts (5) and (11) suggest that irreversible changes of disc height are associated with the adaptation of the intervertebral discs to alterations in the prevailing mechanical (functional) conditions within the vertebral column during aging.

Most human aged 30 and more show degenerative changes in the intervertebral discs (12). Degenerated discs have a decreased height due to the reduced hydration capacity and the more fibrotic appearance of the nucleus pulposus(13). The cross-sectional area of the adjacent vertebral endplates is increased because of the presence of vertebral osteophytes. In degenerated soft tissue there is a loss of swelling pressure and an increase in matrix deformation (14\&15).

Degenerative process of the spine is usually divided into three phases; inflammatory, instability, and re-stabilization (16). Although these arthritic changes are more common in the area with greater mobility and pressure like lower cervical or lower lumbar spine, different stages of arthrosis can be observed simultaneously in one region of the spine (17). Lumbar spondylosis is not synonymous with lumbar spinal stenosis (LSS), but it comprises the vast majority of these cases (18).

The present study aimed to the examination of possible age related changes in the lumbar spine in Egyptian people detected by MRI.

\section{Patients and Methods}

\subsection{Materials and Subjects}

Eighty symptomless persons (30 females and 50 males) between 25- 70 years of age were included in this study. All underwent midsagittal magnetic resonance imaging of their lumbar region. The midsagittal magnetic resonance imagings were obtained in the department of radiology, Zagazig University Hospital, Egypt. It was ensured that they were free from any history of trauma or any systemic inflammatory disease. The subjects were divided into 2 age categories; the first category included subjects between 25 to 40 years of age ( 40 cases), the second between 41 to 70 years (40 cases).

Before undertaking MRI, a spinal surgeon conducted examination of the spine including a neurological examination.Patients with back pain, weakness or pain in the lower extremities, sensory disturbance or abnormal deep tendon reflexes of the lower extremities were excluded from the study. Five lumber intervertebral levels from L1/L2 to L5/S1 were evaluated for the study.

\subsection{Data Management}

The clinical data were recorded on a report form. These data were tabulated and analyzed using the computer program SPSS (Statistical package for social science) version 16 to obtain.

\subsection{Descriptive Data}

Descriptive statistics were calculated using frequency and distribution for qualitative data.The significance of difference was tested using Inter-group comparison of categorical data was performed by using chi square test $\left(X^{2}\right.$ value).A $P$ value $<0.05$ was considered statistically significant (S), while $\mathrm{P}>0.05$ wasstatistically insignificant, $\mathrm{P}$ value $<0.01$ was considered highly significant (HS) in all analyses.

\section{Results}

Normal MRI findings which include normal alignment, normal lordotic spine, normal disc spaces, and normal vertebral body heights as shown in (Figure 5, 6 and 7). These features were obvious in the group one (aged from 25-40 years).

The degenerative changes which include loss of lumbar spine curvature, disc space narrowing and disc prolapse, osteophytic changes and subchondral multiple small cysts (Figure 1, 2, 3, 4, 8 and 9).These changes were seen on both groups, however, more evident in the second group (41-70 years). 

Resonance Imaging (MRI).

Table 1.The frequency of age, gender and different diseases.

\begin{tabular}{|c|c|c|}
\hline & No (80) & $\%$ \\
\hline \multicolumn{3}{|l|}{ Age group } \\
\hline $25-40$ & 40 & 50.0 \\
\hline $41-70$ & 40 & 50.0 \\
\hline \multicolumn{3}{|l|}{ Sex } \\
\hline Male & 50 & 62.5 \\
\hline Female & 30 & 37.5 \\
\hline \multicolumn{3}{|l|}{ Disease } \\
\hline Normal & 38 & 47.5 \\
\hline Abnormal & 42 & 52.5 \\
\hline \multicolumn{3}{|c|}{ Subchondral cysts } \\
\hline Yes & 42 & 52.5 \\
\hline No & 38 & 47.5 \\
\hline \multicolumn{3}{|l|}{ Osteophytes } \\
\hline Yes & 42 & 52.5 \\
\hline No & 38 & 47.5 \\
\hline \multicolumn{3}{|c|}{ Disc degeneration } \\
\hline Yes & 36 & 45.0 \\
\hline No & 44 & 55.0 \\
\hline \multicolumn{3}{|c|}{ Disc prolapsed } \\
\hline Yes & 30 & 37.5 \\
\hline No & 50 & 62.5 \\
\hline \multicolumn{3}{|c|}{ Spondyolysis } \\
\hline Yes & 30 & 37.5 \\
\hline No & 50 & 62.5 \\
\hline
\end{tabular}

Table 2.The relations between age groups and different diseases.

\begin{tabular}{|c|c|c|c|c|}
\hline Age group & $25-40(\%)$ & $41-70(\%)$ & $X^{2}$ test & P value \\
\hline \multicolumn{5}{|l|}{ Sex } \\
\hline Male & $21(52.5)$ & $29(72.5)$ & 3.41 & 0.065 \\
\hline Female & $19(47.5)$ & $11(27.5)$ & & \\
\hline \multicolumn{5}{|l|}{ Disease } \\
\hline Abnormal & $10(25.0) 30(75.0)$ & $32(80.0)$ & 24.26 & $0.001 * *$ \\
\hline Normal & & $8(20.0)$ & & \\
\hline \multicolumn{5}{|l|}{ Subchondral } \\
\hline Yes & $10(25.0) 30(75.0)$ & $32(80.0)$ & 24.26 & $0.001 * *$ \\
\hline No & & $8(20.0)$ & & \\
\hline \multicolumn{5}{|l|}{ Osteophytes } \\
\hline Yes & $10(25.0) 30(75.0)$ & $32(80.0)$ & 24.26 & $0.001 * *$ \\
\hline No & & $8(20.0)$ & & \\
\hline \multicolumn{5}{|c|}{ Disc degeneration } \\
\hline Yes & $8(20.0)$ & $28(70.0)$ & 20.2 & $0.001 * *$ \\
\hline No & $32(80.0)$ & $12(30.0)$ & & \\
\hline \multicolumn{5}{|c|}{ Disc prolapsed } \\
\hline Yes & $7(17.5)$ & $23(57.5)$ & 13.65 & $0.001 * *$ \\
\hline No & $33(82.5)$ & $17(42.5)$ & & \\
\hline \multicolumn{5}{|l|}{ Spondyolysis } \\
\hline Yes & $7(17.5)$ & $23(57.5)$ & 13.65 & $0.001 * *$ \\
\hline No & $33(82.5)$ & $17(42.5)$ & & \\
\hline
\end{tabular}

Table 3.The relations of sex groups to different diseases.

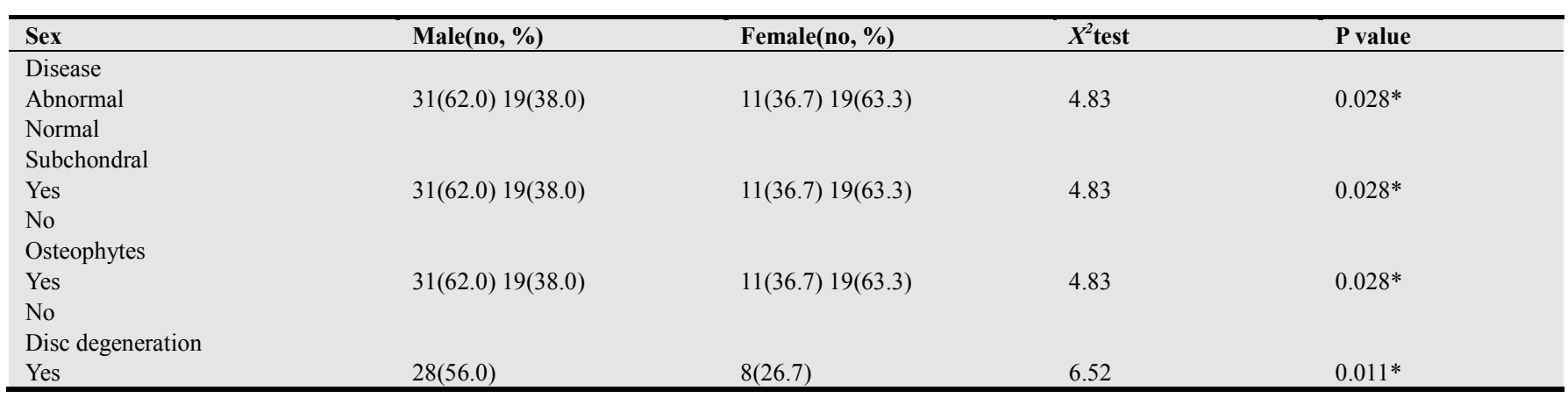




\begin{tabular}{|c|c|c|c|c|}
\hline Sex & Male(no, \%) & Female(no, \%) & $X^{2}$ test & P value \\
\hline No & $22(44.0)$ & $22(73.3)$ & & \\
\hline \multicolumn{5}{|c|}{ Disc prolapsed } \\
\hline Yes & $22(44.0)$ & $8(26.7)$ & 2.4 & 0.121 \\
\hline No & $28(56.0)$ & $22(73.3)$ & & \\
\hline \multicolumn{5}{|c|}{ Spondyolysis } \\
\hline Yes & $22(44.0)$ & $8(26.7)$ & 2.4 & 0.121 \\
\hline No & $28(56.0)$ & $22(73.3)$ & & \\
\hline
\end{tabular}

In table 1 , the collected samples are 80 cases and were divided into 2 groups; the first group is formed of 40 subjects, forming $50 \%$ of all cases with age range $25-40$ years, however, the second group is formed of 40 cases, forming $50 \%$ of all cases with age range $41-70$ years.For gender, there were 50 males $(62 \%)$ of all cases and 30 females , forming $(37.5 \%)$ of cases.From all samples, there are 38 normal $(47.5 \%)$ and the abnormal cases are 42 $(52.5 \%)$. It was found that 42 cases have subchondral cysts, 42 cases have osteophyts which represent $52.5 \%$, Disc degeneration is found in 36 cases about $45 \%$, while disc prolapse is present in 30 cases $(37.5 \%)$ and spondylosis is present in 30 cases $(37.5 \%)$.

In table 2, the relation between the age groups and different diseasesrelated to the lumbar vertebrae, it was found that males are more prone to be affected than females, where the frequency and distribution of diseases by using intergroup comparision of categorical data ( $\mathrm{x}^{2}$-test) was 3.41,however, $\mathrm{p}$ value was insignificant, as regards comparison between normal and abnormal subjects, we found that the abnormality was more in males than females where $\mathrm{x}^{2}$ - test equales 24.26 , with highly significant $P$ value $(\mathrm{p}=0.001)$. The distribution of subchondral was more in males than females where $\mathrm{x}^{2}$ - test is 24.26 also with highly significant $P$ value, $(p=0.001)$ and also in all other sorts of lumbar lesions.

In table 3, which shows the relation of sex groups to different diseases, it was found collectively that the abnormalities are more in males than females and that was supplemented by $\mathrm{x}^{2}$ - test (4.83) and $\mathrm{p}$ value (0.028).Also, in all sorts of lesions in lumbar region where subchondral was more in males, also osteophytes and disc degeneration where $\mathrm{x}^{2}$ - test and $\mathrm{P}$ values were $, 4.83 \& 0.028,4.83 \& 0.028$ and $6.52 \& 0.011$ respectivelly, and for disc prolapse and spondylosis it was also more previlant in males but with non significant $P$ value, $(p=0.121)$.

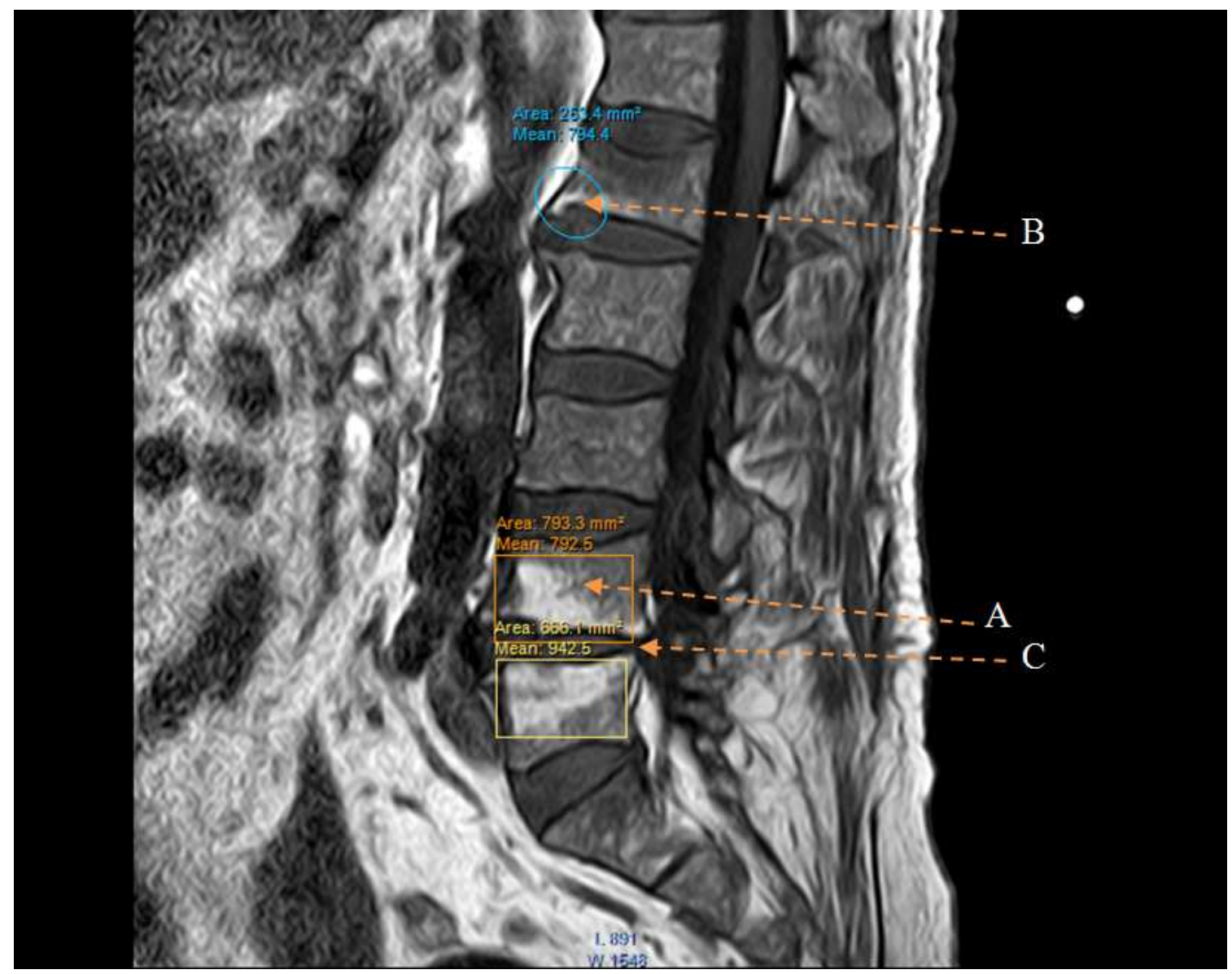

Fig. 1. MRI of male patient aged 45 years old showing, (A)subchondral sclerosis, (B)osteohpytes formation, and (C)disc degeneration and diagnosed as lumber spondylosis. 

Resonance Imaging (MRI).

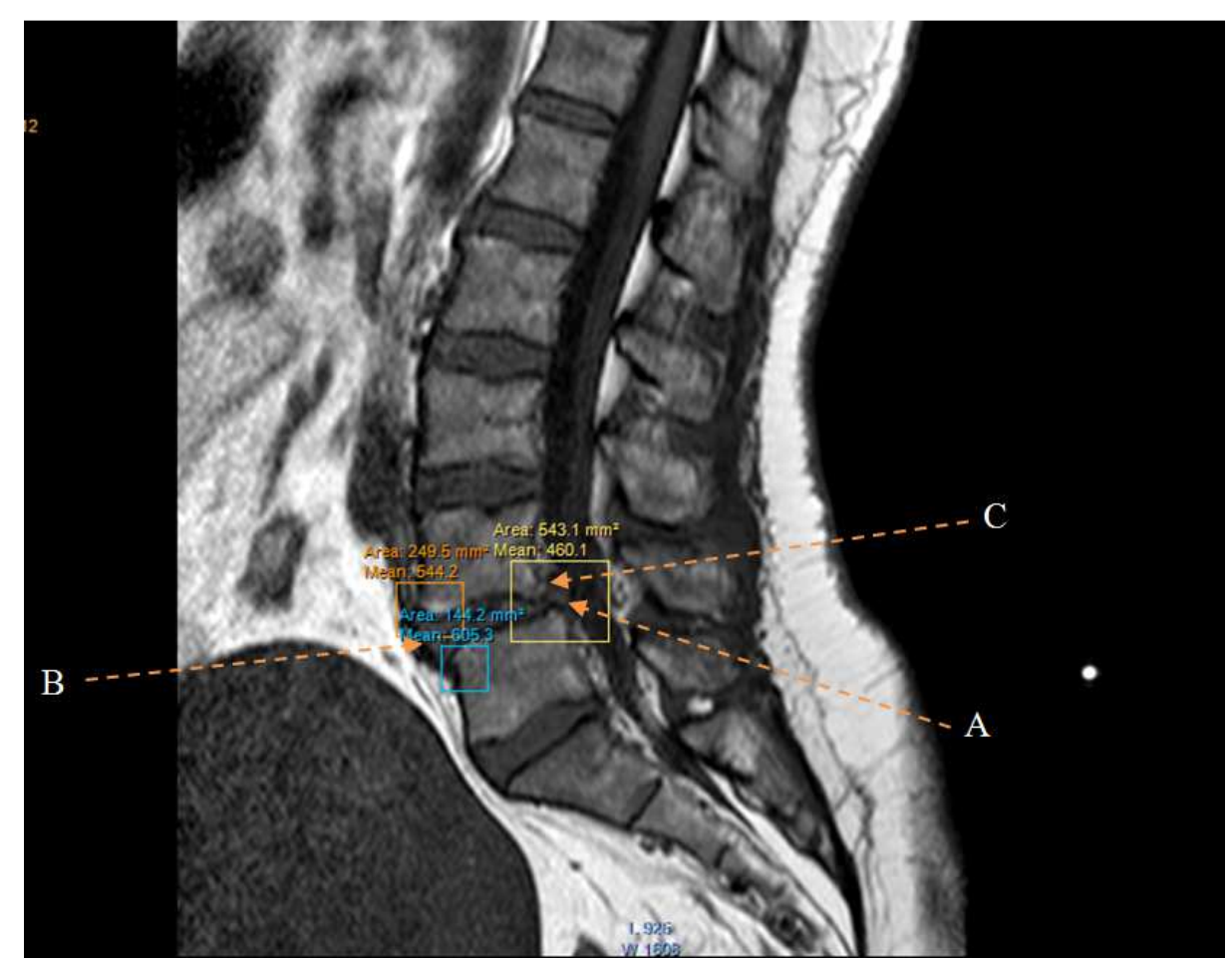

Fig. 2. MRI of female patient aged 40 years old showing, (A)disc prolapse of L4 - L5, (B)degenerative changes L4 \& L5, and (C)spondylolysis L4 - L5.

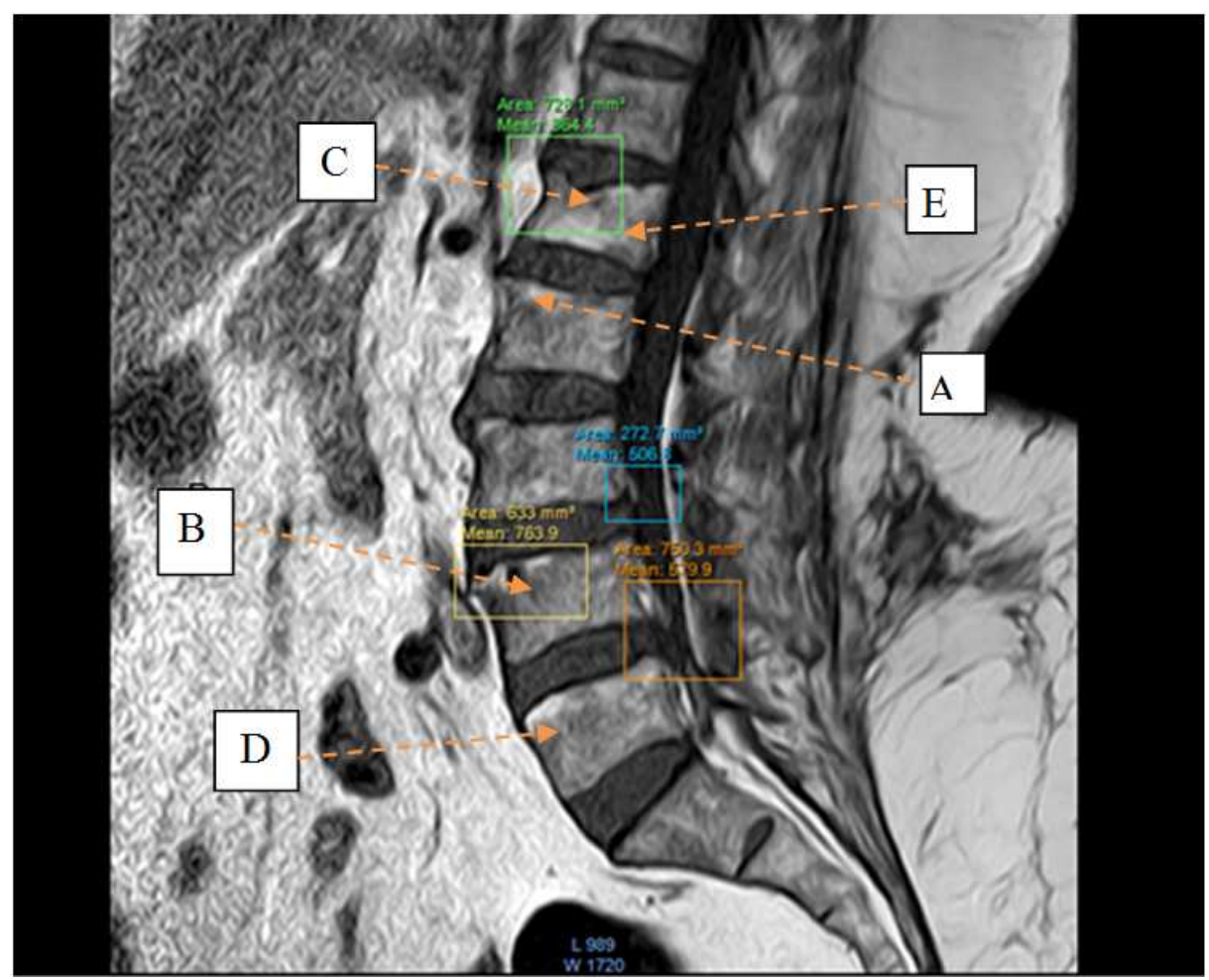

Fig. 3. MRI of female patient aged 65 years old showing, (A)osteophytes formation, (B)subchondral cyst, (C)osteoporosis, (D)subchondral sclerosis, (E) wedging of $L 1$ vertebra and (F) disc bulge of $L 4-L 5$. 


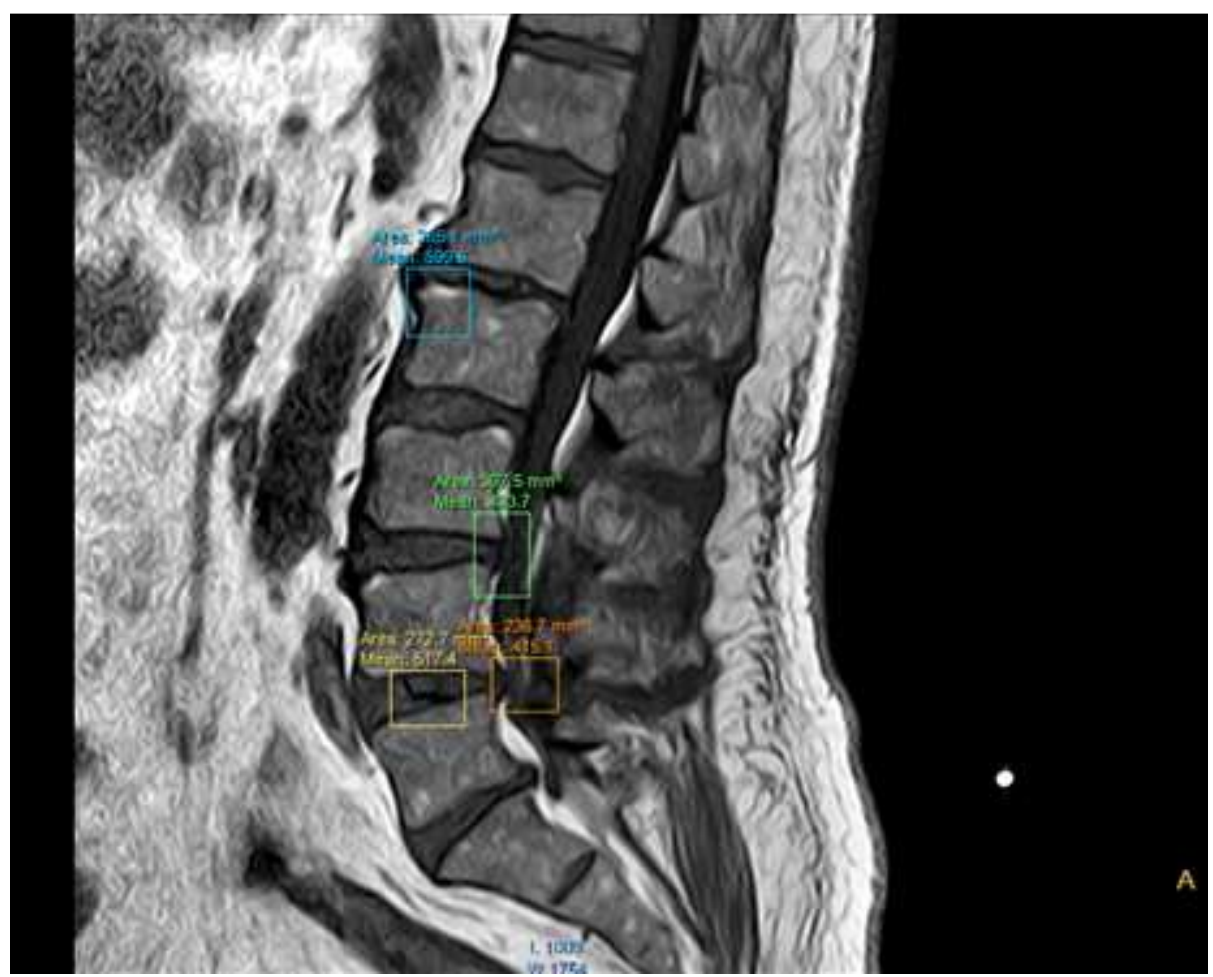

Fig. 4. MRI of male patient aged 35 years old showing, degenerative changes in form of (A)subchondral sclerosis \& osteophytes, (B)disc lesion of L4- L5 with bulge indenting nerve root and (c) disc bulge of $L 5-S 1$.

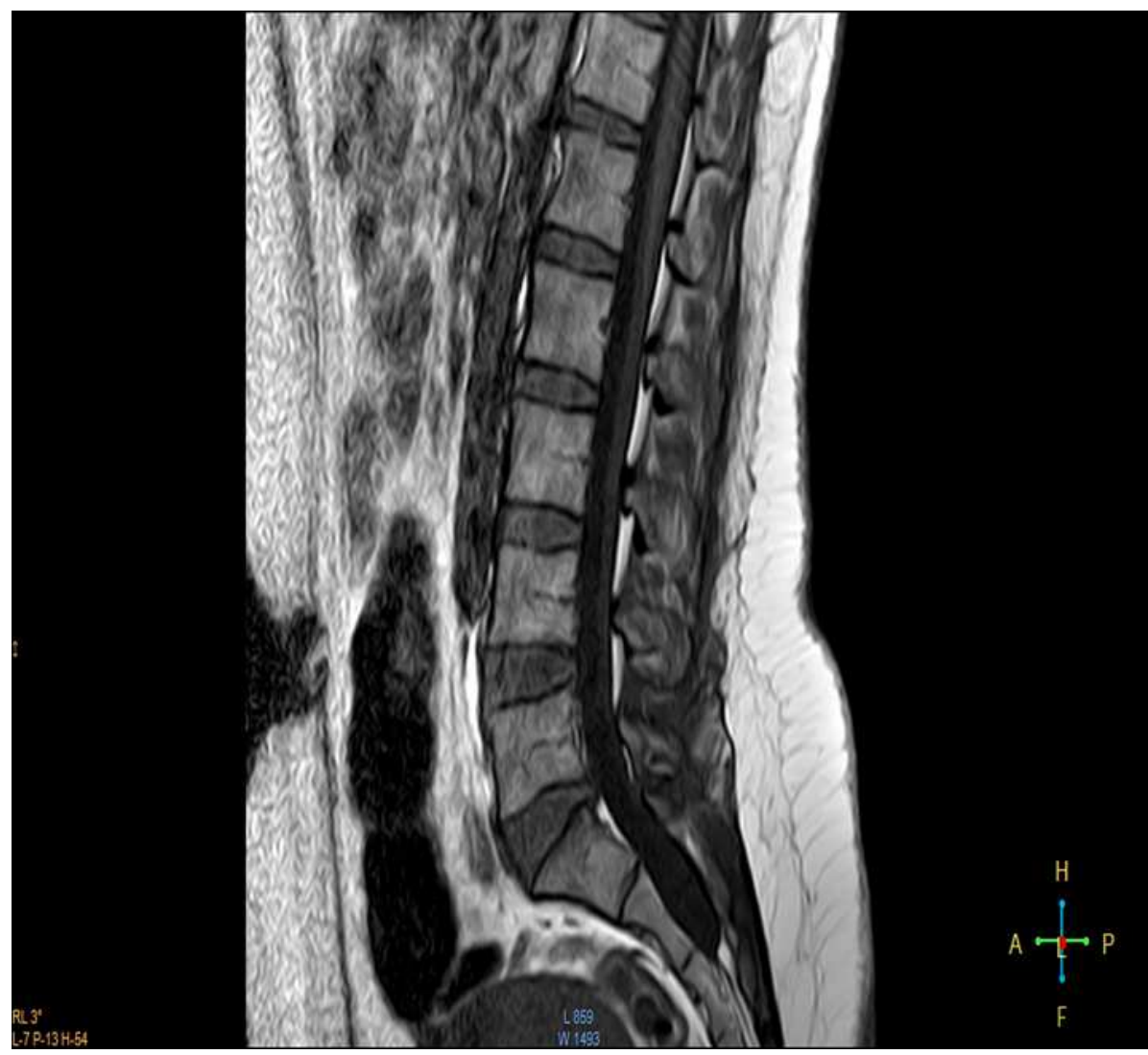

Fig. 5. MRI of female patient aged 28 years old showing,normal radiological features. 

Resonance Imaging (MRI).

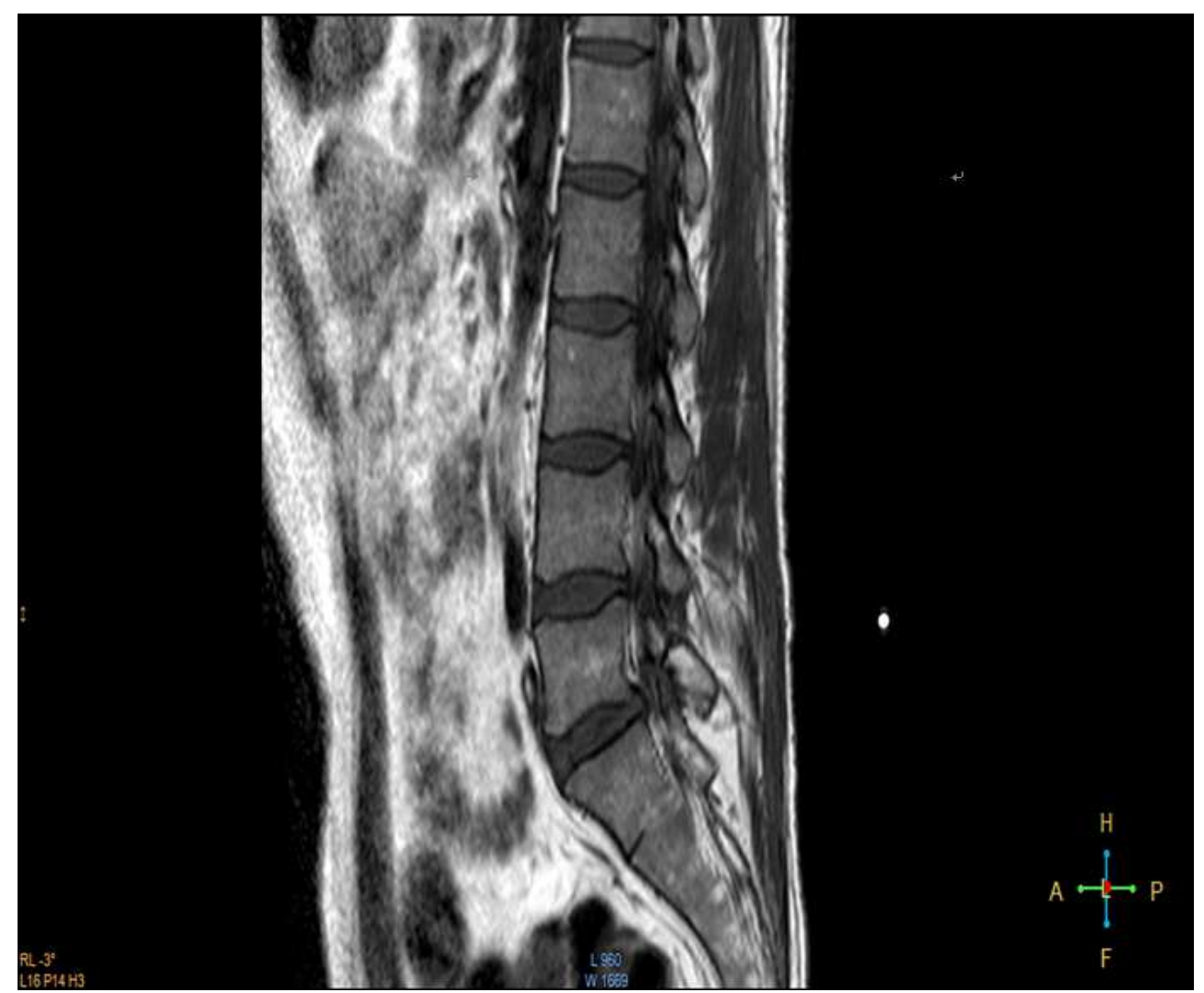

Fig. 6. MRI of male patient aged 22 years old showing, normal radiological features.

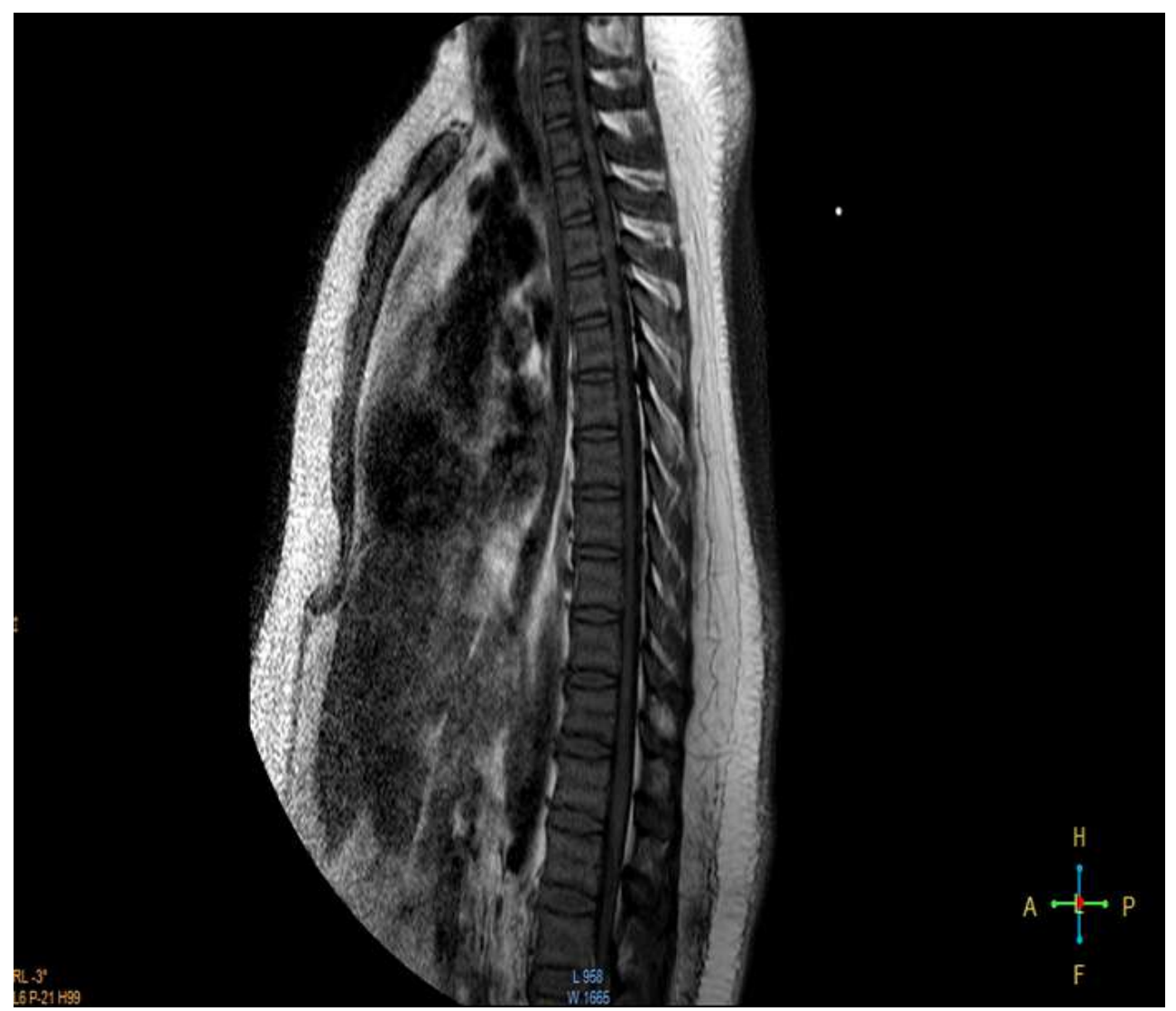

Fig. 7. MRI of male patient aged 32 years old showing,normal radiological features. 


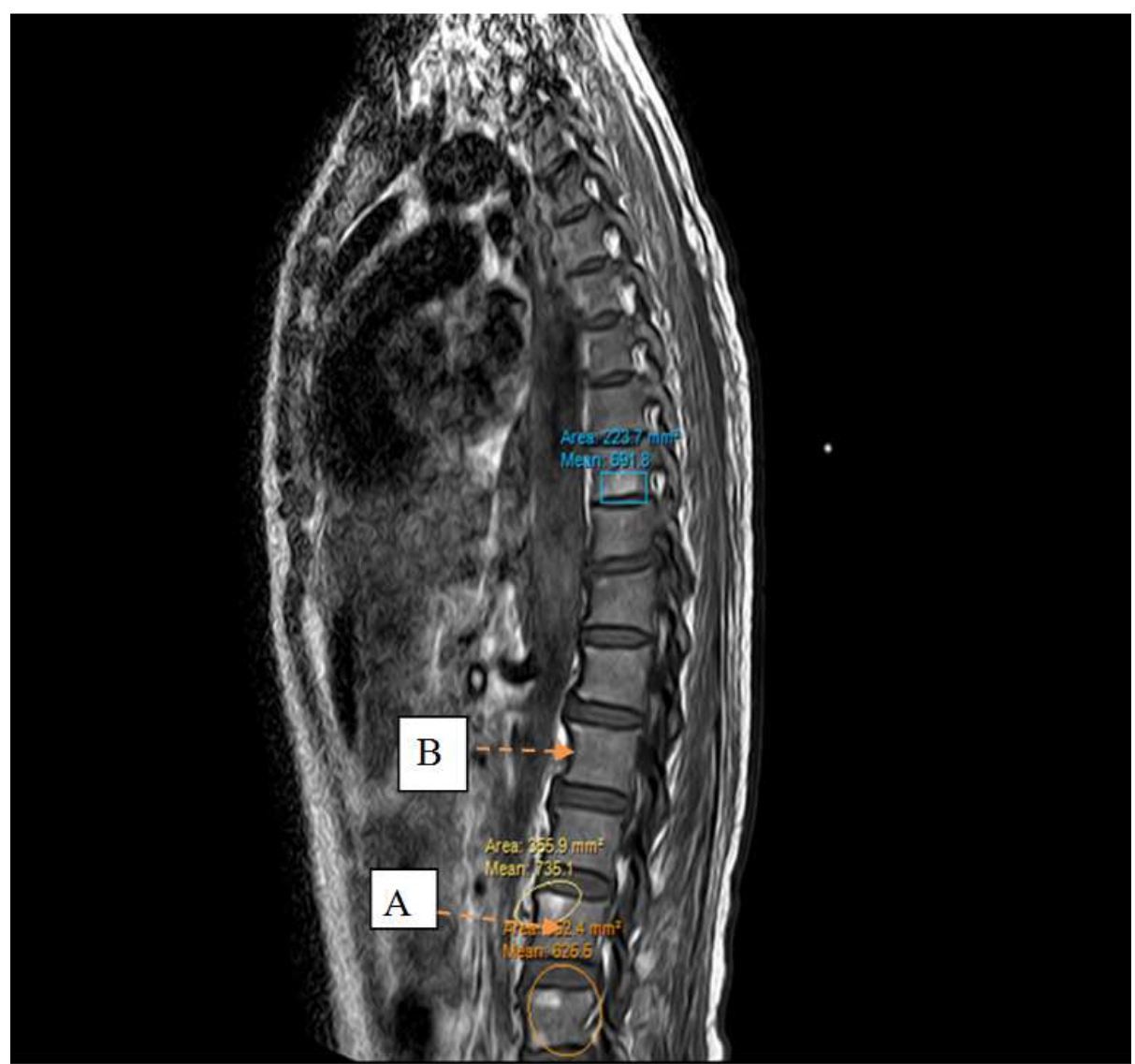

Fig. 8. MRI of male patient aged 40 years old showing, Lumber spondylosis in the form of (A)subchondral sclerosis \& (B)osteophytes formation.

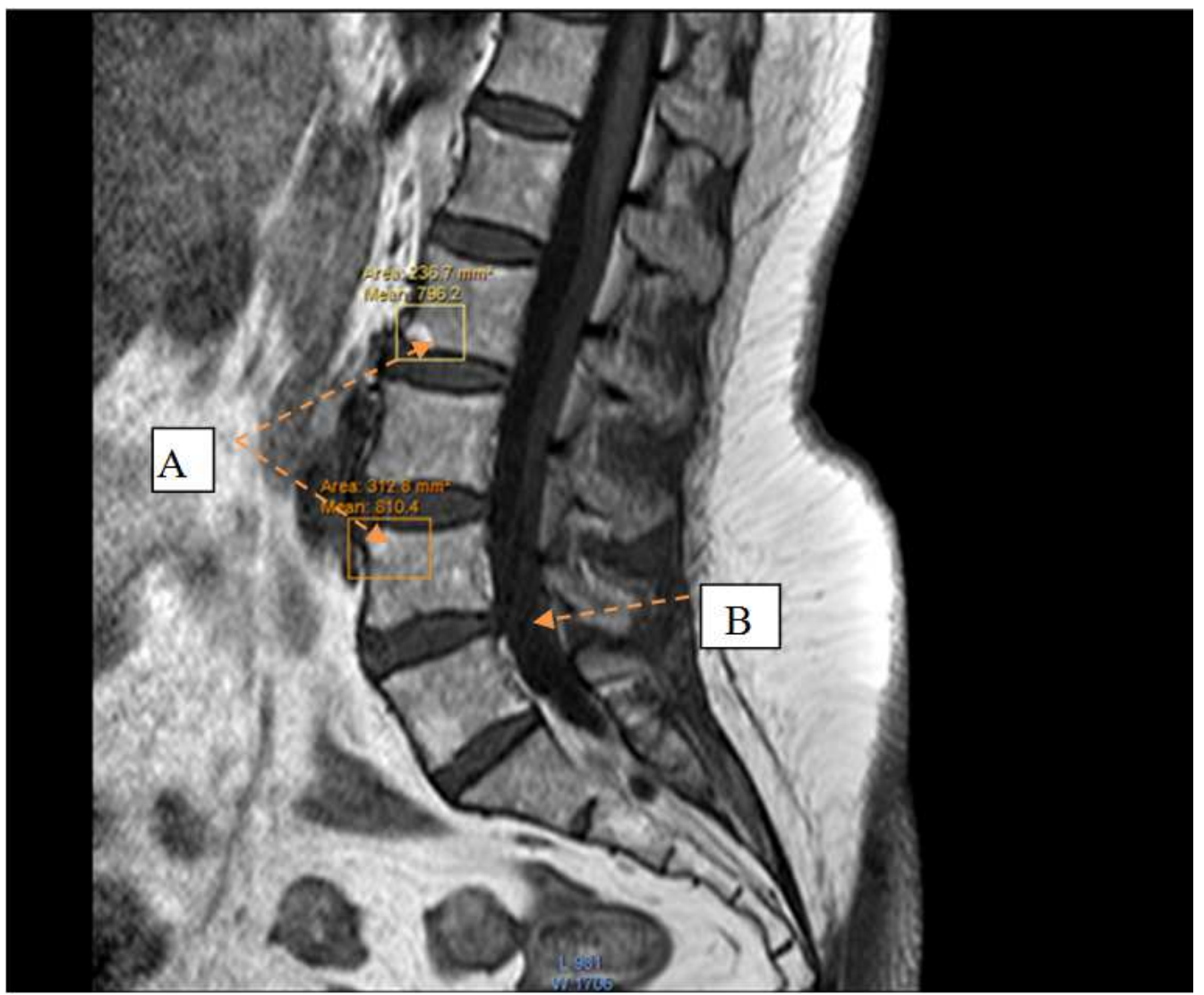

Fig. 9.MRI of female patient aged 40 years old showing, (A) small osteophyte $L 2 \& L 4 \&$ (B) exaggerated lumber lordosis. 


\section{Discussion}

In the present study the MRI used as diagnostic method in the study of age changes in lumber region. This is in line with (19) who stated that MRI provides a precise representation of the anatomy of the disc, spinal canal, and disco-vertebral complex, information that will allow accurate diagnosis of degenerative disc disease.

A systematic review involving spinal MRI, found MRI to be a highly sensitive for lumbar spinal conditions, high sensitivity ranging between $89-100 \%$ for disc herniation studies. (Janssen et al 1994) (20), and Jarvik JG, Deyo RA, 2002 (21) Reported that the quality of these images allows the diagnostician to make more detailed and accurate assessments of the intervertebral disc and its relation to the neural structures when compared with more traditional methods, such as lumbar and computed tomography (CT) myelograms.

In the present study there are very important radiological features; subchondral sclerosis, osteophytes formation, and disc degeneration, which appear as age related changes, these results are in agreement with (22), who reported that strong associations between the presence of enthesophytes, osteophytes and bone sclerosis at various joint sites have been shown.

In the present work the osteophytes more obvious and increase with the increasing in age, many authors accepted that the vertebral osteophyte formation is a well-documented phenomenon that is associated with degeneration and altered mechanics of the spine, both of which have been considered to be the result of aging, a purely physiologic response to load bearing, or intrinsic spinal disease as etiologic factors (23\&24). They are recognized radiologically as hyperostosis at the region of the attachment of the annular fibers to the vertebral body and localized increases in bone mineral density (25).

The disc space narrowing in this study was due to cartilage loss, it is in line with Sofamore, 2002(26), who found that the degenerative disc disease is part of the natural process of growing older.Unfortunately, as we age, our intervertebral discs lose their flexibility, elasticity and shock absorbing characteristics. According to Buckwalter et al., 1995(8); during the degeneration process, the discs undergo progressive structural changes in the form of dehydration of the nucleus and disintegration of the annulus fibrosus resulting in decreased disc height, and lead to an increase in the compression stiffness and reduction in disc fiber strain

Peripheral joint osteoarthritis in the present study is characterised radiologically by the presence of osteophytes, subchondral sclerosis and joint space narrowing this in agreement with Stephen, et al.2007 (27) who found that joint space narrowing is due to cartilage loss, whereas both subchondral sclerosis and osteophyte are hypertrophic responses of bone, thought to arise directly either to cartilage loss or to biomechanical stress. Degenerative joint disease is a degradative process of the joints that primarily involves the articular cartilage (28). This disease is the leading cause of chronic disability all over the world and usually presents with joint pain, tenderness, stiffness, locking, and effusion (29). The arthritic changes in the spinal column (spondylosis) with involvement of the facet joints and intervertebral discs, in addition to these common signs and symptoms, may also cause neurologic impingement (30\&31).

In this work there is a spinal canal stenosis which is refered to narrowing of the spinal canal. Many previous studies have suggested that degenerative LSS begins with the loss of disc height resulting in annulus fibrosis and foraminal stenosis, and these changes alter the loading of the facet joints, leading to facet arthrosis, ligamentumflavum thickening, and osteophyte formation at the end- plate.Lumbar spinal stenosis is the most frequent indication for spinal surgery in people over 60 years old (32). Also, (Urrutia VE, et al. 2009) (33) said that, the number of patients with degenerative ailments of the lumbar spine is increasing, which appears to be a usual result of aging due to the increase in life expectancy. It is estimated that between $70-90 \%$ of the general population suffer from low back pain and that about $4 \%$ require operation at certain time.

In conclusuion it was found that, the lumbar region affected early by the age and more affected in males than in females, and the degeneration accelerates after the age of 50

\section{References}

[1] Whitcome KK, Shapiro LJ and Lieberman DE (2007): Fetal load and the evolution of lumbarlordosis in bipedal hominins. Nature 450: 1075 - 1078.

[2] Steele DG and Bramblett CA (1988): The Anatomy and Biology of the Human Skeleton. TexasA\&M Press: College Station, TX: $56-57,75,104-157,164,228$.

[3] Lance Twomey L., , Taylor J. (1994):The lumbar spine: structure, function, age changes and physiotherapy. Australian Journal of Physiotherapy. Volume 40, Supplement, 1994, Pages 19-30.

[4] Ashman RB : Disc anatomy and biomechanics. Spine State Art Rev 1989;3: 13-26.

[5] Humzah MD, Soames RW: Human intervertebral disc: structure and function [Review]. Anat Rec 1988;220:337-56.

[6] Errington RJ, Puustjarvi K, White IR, Roberts S, Urban JP:Characterisation of cytoplasm-filled processes in cells of the intervertebral disc. J Anat1998, 192:369-378.

[7] Bruehlmann SB, Rattner JB, Matyas JR, Duncan NA: Regional variations in the cellular matrix of the annulus fibrosus of the intervertebral disc. J Anat2002, 201:159-171.

[8] Buckwalter JA: Spine update: Aging and degeneration of the human intervertebral disc. Spine 1995;20:1307-14.

[9] Malcolm, G.P. (2002): Surgical Disorders of the Cervicalspine: Presentation and Management of Common Disorders. Journal of Neurology, Neurosurgery \& Psychiatry, 73, i34-i41. 
[10] Chawla K, Sharma M, Abhaya A, Kochhar S: Morphometry of the lumbar pedicle in North West India. Eur J Anat 2011; 15(3): 155-61.

[11] Oda J, Tanaka H, Tsuzuki N: Intervertebral disc changes with aging of human cervical vertebrae from the neonate to the eighties. Spine 1988;13: 1205-1.

[12] Miller, J.,Schmatz, C., Schultz, A., 1988: Lumbar disc degeneration: correlation with age, sex, and spine level in 600 autopsy specimens. Spine 13, 173-178.

[13] Gunzburg, R., Parkinson, R., Moore, R., Cantraine, F., Hutton, W.,Vernon-Roberts, B., Fraser, R., 1992: A cadaveric study comparing discography, magnetic resonance imaging, histology, and mechanical behavior of the human lumbar disc. Spine 17, 417-426.

[14] Iatridis, J.C., Setton, L.A., Foster, R.J., Rawlins, B.A., Weidenbaum, M., Mow, V.C., 1998: Degeneration affects the anisotropic and nonlinear behaviors of human anulusfibrosus in compression. Journal of Biomechanics 31, 535-544.

[15] Urban, J.P., McMullin, J.F., 1988: Swelling pressure of the lumbar intervertebral discs: influence of age, spinal level, composition, and degeneration. Spine 13, 179-187.

[16] Yong-Hing K: Pathophysiology and rationale for treatment in lumbar spondylosis and instability. ChirOrganiMov 1994;79:3-10.

[17] Leone A, Guglielmi G, Cassar-Pullicino VN, BonomoL: Lumbar intervertebral instability: a review. Radiology 2007;245:62-77.

[18] Lee JY, Whang PG, Lee JY, Phillips FM, Patel AA: Lumbar spinal stenosis. Instr Course Lect 2013;62: 383-96.

[19] Modic MT, Ross JS: Lumbar degenerative disk disease. Radiology 2007;245:43-61.

[20] Anssen ME, Bertrand SL, Joe C, Levine MI: Lumbar herniated disk disease: comparison of MRI, myelography, and post-myelographic CT scan with surgical findings. Orthopedics 1994;17:121-7.

[21] Jarvik JG, Deyo RA: Diagnostic evaluation of low back pain with emphasis on imaging. Ann Intern Med 2002;137:586-97.

[22] Rogers J, Shepstone L, Dieppe P: Is osteoarthritis a systemic disorder of bone? Arthritis Rheum. 2004, 50452-457.457
[23] Lane, NE.; Nevitt, MC.;Genant, HK. \&Hchberg, MC. (1993): Reliability of new indices of radiographic osteoarthritis of the hand and hip and lumbar disc degeneration. J Rheumatol Vol. 20, No.11, pp. 1911-1918, ISSN 0315-162X

[24] O’Neill, TW.; McCloskey, EV.; Kanis, JA.; Bhalla, AK.; Reeve, J.; Reid, DM.; Todd, C.; Woof, AD. \&Silman, AJ. (1999): The distribution, determinants, and clinical correlates of vertebral osteophytosis: a population based survey. J Rheumatol Vol. 26, No.4, pp. 842-848, ISSN 0315-162X

[25] Nathan, M.; Pope, MH. \&Grobler, LJ. (1994): Osteophyte formation in the vertebral column: A review of the etiologic factors- Part 1. Contemporary Orthopaedics Vol. 29, No. 1, pp. 31-37, ISSN 0194-8458

[26] SofamoreDanek :Degenerative Disc Disease Back Pain Resources including back pain treatmentoptions symptoms and much more, Back. Com, published Juana, 15, 2002, updated July, 17,2008.

[27] Stephen R Pye, David M Reid, Mark Lunt, Judith E Adams, Alan J Silman, and Terence W O'Neill: Lumbar disc degeneration: association between osteophytes, end-plate sclerosis and disc space narrowing. Ann Rheum Dis. 2007 Mar; 66(3): 330-333.

[28] Samuels J, Krasnokutsky S, Abramson SB: Osteoarthritis: a tale of three tissues. Bull NYU HospJt Dis 2008;66:244-50.

[29] Arden NK, Leyland KM. Osteoarthritis year 2013 in review: clinical. Osteoarthritis Cartilage 2013;21: 1409-13.Schulte TL, Bullmann V, Lerner $\mathrm{T}$, et al: Lumbar spinal stenosis. Orthopade 2006;35:675-92.

[30] Goh KJ, Khalifa W, Anslow P, Cadoux-Hudson T, Donaghy M: The clinical syndrome associated with lumbar spinal stenosis. EurNeurol 2004;52:242-9.

[31] Abbas J, Hamoud K, May H, Hay O, Medlej B, Masharawi Y, et al.: Degenerative lumbar spinal stenosis and lumbar spine configuration. Eur Spine J 2010;19:1865-73

[32] Urrutia VE, Eloizondo ORE, De La Garza CO, Guzman LS: Morphometry of pedicle and vertebral body in a Mexican population by CT and Fluroscopy. Int J Morphol 2009; 27(4): 1299-1303. 